\title{
Effect of UV-B radiations on mortality and enzymes level in fish larvae of Tor tor and Schizothorax richardsonii on laboratory scale
}

\author{
Sunil Kumar \\ Department of Zoology, D.A.V. College, Dehradun (Uttarakhand), India \\ D.S. Malik* \\ Department of Zoology and Environmental Science, Gurukul Kangri Vishwavidyalaya, \\ Haridwar (Uttarakhand), India \\ Prachi Rathi \\ Department of Zoology and Environmental Science, Gurukul Kangri Vishwavidyalaya, \\ Haridwar (Uttarakhand), India
}

*Corresponding author. E-mail: malikdsgkv@gmail.com

\begin{abstract}
Depletion of stratospheric ozone layer is resulting into increase in solar UV-B on earth surface. Ultra violet radiation is well known to cause many detrimental effects in aquatic organisms. The present study was performed to study the effect of solar ultraviolet radiation on fish fingerlings of Tor tor and Schizothorax richardsonii as a model system on laboratory scale. The effect of different intensities of natural solar and artificial UV-B radiation on fish larvae of $T$. tor and $S$. richardsonii in a presence of retene was investigated. Solar ultraviolet intensity showed seasonal and altitudinal variations in Garhwal region. Solar UV radiation level was lower $\left(0.390 \mathrm{mw} / \mathrm{cm}^{2}\right)$ in the month of January- February at lower altitude and highest $\left(1.192 \mathrm{mw} / \mathrm{cm}^{2}\right)$ in the month of July-August 2018 at higher altitude. Fish larvae exposed to artificial UV-B (average wavelength $312 \mathrm{~nm}$ and intensity of $\left.750 \mathrm{mw} / \mathrm{cm}^{2}\right)$ with retene $(50 \mu \mathrm{g} / \mathrm{l})$ showed increase in gills malandialdehyde level and caused larvae mortality as indicating that enhanced solar UV-B exposure could be lethal to fish fauna in aquatic ecosystem. Artificial UV-B had a stronger damaging effect on fish larvae than solar radiation exhibited highly toxic in presence of retene. The larvae of $S$. richardsonii was found more sensitive than $T$. tor as indicated by high mortality rate $(30 \%)$ and high pigmented characteristics on dorsal side. The solar and ultraviolet radiation showed a positive effect on high pigmentation. These results suggest that on a short time scale, UV-B radiation causing developmental stress on fish larvae may contribute to assess the phototoxic behaviour of cold water fishes.
\end{abstract}

Keywords: Fish larvae, Fish mortality, UV-B radiation, Tor tor, Schizothorax richardsonii

\section{Article Info}

DOI:10.31018/jans.v11i2.2080

Received: April 29, 2019

Revised: May 30, 2019

Accepted: June 5, 2019

\section{How to Cite}

Kumar, S. et al. (2019) Effect of UV-B radiations on mortality and enzymes level in fish larvae of Tor tor and Schizothorax richardsonii on laboratory scale. Journal of Applied and Natural Science, 11 (2): $462-467$ https://doi.org/10.31018/ jans.v11i2.2080

\section{INTRODUCTION}

Stratospheric ozone depletion, e.g., the ozone "hole", with the concomitant increase of the most energetic and potentially damaging daylight component UV-B, 280-315 $\mathrm{nm}$ (Madronich,1993), is a cause of great concern under global climate change. Intensity of solar UV-B radiation and the depth of UV penetration in to the water column are key factors in assessing the ecosystem potential for damage to aquatic organisms (Blautein et al., 2002). Consequently, many studies carried out during the last decades have focused on determining solar ultraviolet (UVR- 280-400nm) fluxes reaching the Earth's surface (Frederick et al., 1994), and effects upon various organisms were observed (Figueroa et al., 1996 and De Mora et al., 2000). In addition to the enhanced solar UV-B radiation caused by the stratospheric ozone de- pletion, it has now been recognized that normal solar UVR can also cause ecological stresses on aquatic organisms because they are very sensitive to ambient levels of UVR.

Living organisms of different communities vary in their responses towards ultraviolet radiation which largely depend on dose and duration of exposure of UVR and protective mechanism of the organism being exposed. Exposure of fish larvae towards UV radiation impacted negatively on their survival ratio and ultimately effect to ecosystem productivity in aquatic ecosystem. U-B radiation may impose considerable physiological stress and pathological effect resulting in a number of manifestations such as reduced growth, photoallergy, phototoxicity, photoaggravated skin diseases, increased rates of mortality, inhibition of growth rates and changes mortality (Sommaruga et al., 1996). Impaired reproduction, predisposition to 
diseases, reduced locomotory and predatory performances, or reduced capacity to tolerate subsequent stress (Scott et al., 2004 and Arts et al., 2010). Since many of the physiological conditions get affected by some very important factors(water temperature, diet, dissolved oxygen, $\mathrm{pH}$, total hardness etc.) of aquatic ecosystem. UV-B radiation has severe effects on early life intervals of fishes such as lesions in the brain and retina, and reduced growth rate (Markkula et al., 2009). On the other hand, fish have physiological, morphological and behavioural mechanisms of photoprotection, such as screening pigments (mycosporine -like amino acids and melanin), photorepairing (photolyase), excision repair, and avoidance behaviour (Speekmann et al., 2000). In fish species, melanin pigmentation seems to provide an efficient photoprotection mechanism (Lin and Fisher, 2007). Exposure of UV- B radiation with retene and riboflavin cause increase in gill malandialdehyde and decrease in glutathione content. Artificial UV-B had a stronger damaging effect than solar radiation and became highly toxic in presence of retene (Kumar et al., 2011). Dargaei et al., (2014) studied UV-B impacts on morphology and retina of Oncorhynchus mykiss larvae and concluded that the harmful effect of ultraviolet radiation on aquatic animals, due to ozone depletion a wide variety of body abnormalities and eye damages, none of the malformations were observed in control group. Several studies have reported that UV radiation reduces survival of fish larvae. UV-B radiation may impose considerable damaging of stem cell DNA, contribute to depletion of stem cells (ESCs and mesenchymal stem cells) and damage of stem cell niche, eventually leading to photoinduced skin aging (Uraiwan., et al., 2015).

Because of lack in systematic and scanty scientific knowledge of phototoxicity on fish larvae and due to enhance of solar ultraviolet radiation in Himalayan region, an attempt has been made to assess the adverse effects of UV-B on metabolism and mortality rate of selected fish larvae of species, $T$. tor and S. richardsonii in laboratory condition.

\section{MATERIALS AND METHODS}

Uttarakhand Himalayan region situated between latitude from $28^{\circ} \mathrm{C} 21^{\prime}$ to $30^{\circ} 21^{\prime}$ North Latitude and $78^{\circ} 30^{\prime}$ to $80^{\circ} 30^{\prime}$. Different altitudinal sites were selected i.e. Haridwar (314 msl), Dehradun $(450 \mathrm{msl})$, Tehri $(1850 \mathrm{msl})$, Mussoorie $(2100 \mathrm{msl})$ and Chamoli (3000 msl) for monitoring of natural solar radiation and measured every month by using Cole-parmer radiometer (U.S.A) having Vilber Laurmat France calibrated UV sensors with spectral sensitivity $312 \mathrm{~nm}$ was performed in a year 2017-18 between 11:00am - 2:00pm for 3 hours on clear sunny days to compare the altitudinal differences in natural solar UV-B radiation.
Fish larvae (fingerlings) of $T$. Tor and S. richardsonii (weight range between 1.90 to $1.99 \mathrm{gm}$ and size range between 30 to $40 \mathrm{~mm}$ ) were collected from Bhagirathi river, Uttarakhand $\left(30^{\circ} 22^{\prime} 54^{\prime \prime} \mathrm{N}\right.$ latitude and $78^{\circ} 29^{\prime} 3^{\prime \prime}$ E longitude)) using the cast net (Figs. $3 A$ and $B$ ). The fish larvae were initially acclimatized in aquaria on supplementary feeds for two week and then shifted in six experimental aquariums, made up of glass having size dimensions $(60 \mathrm{~cm} \times 45 \mathrm{~cm} \times 38 \mathrm{~cm})$. The experimental aquaria were fitted with vertical moving wooden sheet, which contained plastic mesh containing 120 fingerlings uplifted towards upper water surface on $10 \mathrm{~cm}$ to get maximum exposure of solar and UV radiation. The fish larvae of Tor and Schizothorax fishes were kept on wooden hatching trays at $10 \mathrm{~cm}$ depth from water surface of aquaria (Fig. 1 and 2). The water temperature in the experimental aquaria was maintained between 16.2 to $17.5^{\circ} \mathrm{C}$. Fish fingerlings were well treated to avoid any signs of infection before the experiment. On the basis of experimental design, fish larvae were separated in to six groups 20 larva in each. Group I was kept as control. Group II was exposed to retene, Group III was given natural solar radiation between 11.00 am to $2.00 \mathrm{pm}$ for three hours per day for 30 days during clear weather. Group IV exposed to artificial UV-B and group $V$ exposed to solar radiation and retene. Group VI exposed to artificial UV-B and retene. Concentration of retene (50ug/l) was used as photo sensitizer in experimental aquarium. Artificial ultraviolet- $B$ radiation was given by Philips UV-B lamp with average wavelength $312 \mathrm{~nm}$ for the same duration. Solar UV-B was measured by Cole -Parmer radiometer having Vilber Laurmat France calibrated UV-B sensor. Irradiation was carried out in the sunlight and for enhanced ultraviolet radiations; artificial UV-B lamp was used for scheduled duration (3hrs/day). Different intensity of solar and artificial ultraviolet-B radiation was used in the experiments. Horizontally placed $3 \mathrm{ft}$ long UV tubes were used for irradiation. Irradiation of the emitted light was measured by Cole Parmer Radiometer. After exposure of UV and solar radiation to fish larvae on $10 \mathrm{~cm}$ at water surface, the sieve reverted down to free movement of larvae in aquarium for rest of time. Artificial feed was given to fish larvae in all aquariums twice in a day as per $5 \%$ of body weight. Aerator was used for maintaining the quality parameters of water and related physico-chemical parameters were recorded at regular intervals using multi-parameter autoanalyser and colorimetric method. Mortality rate of $T$. tor and S. richardsonii larvae were recorded on daily basis. For mortality analysis, lipid peroxidation was assayed by measuring of malondialdehyde level in fish fingerlings by using thiobarbiturc acid (TBA) through the method (Smith and Anderson, 1987). The absorbance was recorded using 
UV/ visible spectrophotometer at $532 \mathrm{~nm} .1,1,3$ tetramethoxy propane (Wako, Japan) was used as the standard. Catalase (E.C. 1.1.11.6) $\mathrm{H}_{2} \mathrm{O}_{2}$ $\mathrm{H}_{2} \mathrm{O}_{2}$ oxidoreductase enzyme activity in the fish tissue was determined by breakdown of hydrogen peroxide using titration method (Takahara et al., 1960).Superoxide dismutase (SOD) activity was analysed as larval body analysis as described by (Hakkinen et al.,2004). The SOD activity was measured by the method of (Ukeda et al., 1999).

\section{RESULTS AND DISCUSSION}

The amount of UV-B reaching the surface of earth depends on the thickness of the ozone layer and atmosphere. The variation of UV radiation reaching the earth surface has experimental evidence. It depends upon altitude, atmospheric condition and types of instrument used for measurement (Singh et al., 2012). Erythemal weighed UVR are reported to increase with altitude at an approximate rate of 5 to $7 \%$ per kilometer and showed greatest increase occurring at solar zenith angle (SZA) 60-70 (Zaratti et al., 2003 and Mckenzi et al., 2007). The present study observed that natural solar radiation was lowest in JanuaryFebruary and maximum in a month of July - August and there was about 4.5 to $6.8 \%$ altitudinal increment per kilometer in Garhwal region of Uttarakhand. The results showed that intensity of solar ultraviolet radiation increases with increase in altitude based on seasonal variations (Fig. 4).

Fishes, unlike other surface dwelling organisms, avoid the harmful effect of Ultraviolet radiation by swimming to the deeper portion of the water body. However the effect of UV radiation may be more harmful on developmental and larval stages of fish species in natural aquatic ecosystem. Fish larvae are also affected by different environmental factors such as temperature, $\mathrm{pH}$, light and environmental pollutants (Buzzi, 2002). The water quality

Table 1. Water quality parameters during experiments of fish larvae.

\begin{tabular}{lll}
\hline S.N. & Parameters & Range \\
\hline $\mathbf{1 .}$ & Temperature $\left({ }^{\circ} \mathrm{C}\right)$ & $16.2-17.5$ \\
2. & pH & $7.6-7.8$ \\
3. & TDS $(\mathrm{mg} / \mathrm{l})$ & $120-140$ \\
4. & Conductivity $(\mu \mathrm{S} / \mathrm{cm})$ & $125.8-152.5$ \\
$\mathbf{5 .}$ & Total Hardness $(\mathrm{mg} / \mathrm{l})$ & $89.2-102.3$ \\
$\mathbf{6 .}$ & DO $(\mathrm{mg} / \mathrm{l})$ & $9.1-10.14$ \\
\hline
\end{tabular}

Table 2. Chemical composition of supplementary fish feed.

\begin{tabular}{ll}
\hline Nutrients & Percentage \\
\hline Protein & $40.6 \%$ \\
Fat & $6.6 \%$ \\
Starch & $14.2 \%$ \\
Fiber & $21.1 \%$ \\
Sugar & $1 \%$ \\
Mineral/ash & $12.4 \%$ \\
Moisture & $4.7 \%$ \\
\hline
\end{tabular}

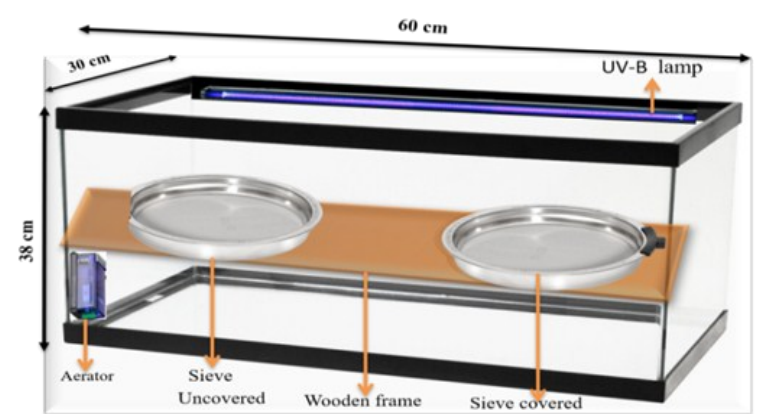

Fig. 1. UV- B exposed and UV-B filtered experimental tank.

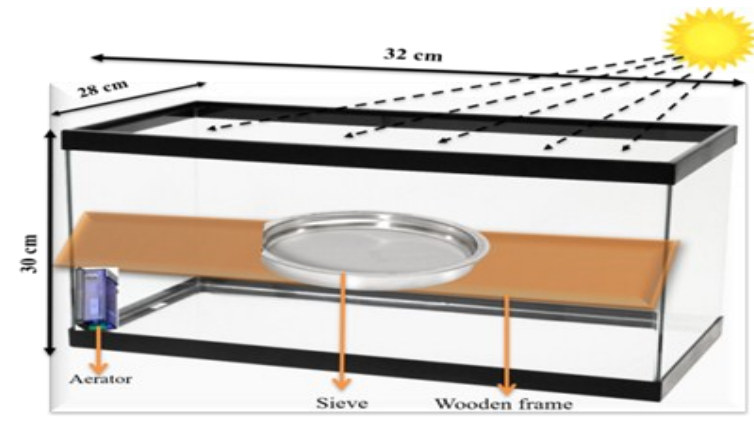

Fig. 2. Natural solar UV exposed experimental tank.

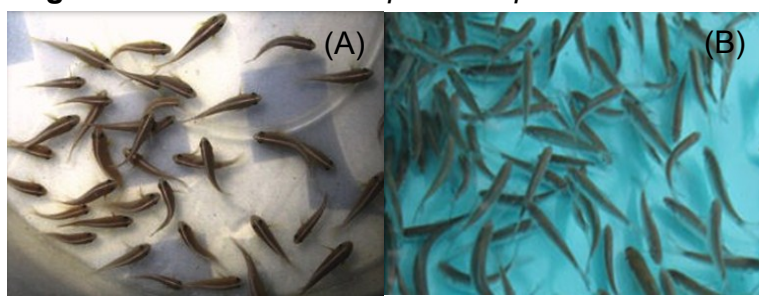

Fig. 3 (A-B). Fingerlings : (A). T. tor (B). S. richardsonii.

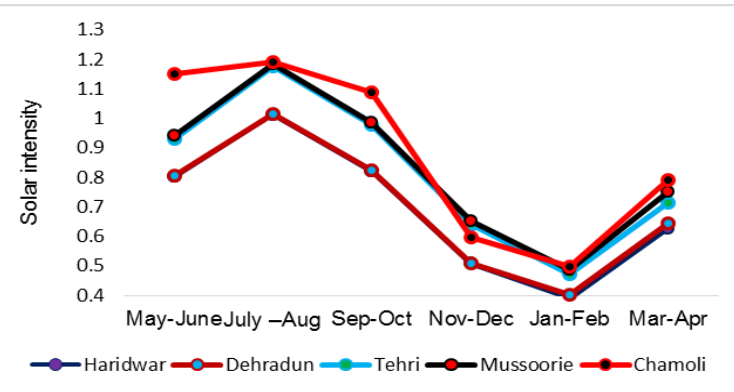

Fig. 4. Seasonal and altitudinal variations of solar UV-B in Uttarakhand region.

parameters in all fish experimental aquariums were maintained as per standard of cultural practices (Table 1). The present range of water temperature and dissolved oxygen contributed as optimum aquatic condition for the survival during the experiment. UV-B also participates in indirect damage to macromolecules, provokes free radical production and induces a significant decrease in antioxidents in biotic organisms (David and Davies, 2006). The hill stream fish species as $T$. tor and $S$. richardsonii, mostly preferred the high protein feed, hence composited supplementary feed of about $40 \%, 21 \%$ and $12.6 \%$ of protein, crude fiber and 
Kumar, S. et al. / J. Appl. \& Nat. Sci. 11(2): 462- 467 (2019)

Table 3. Effect of solar and artificial UV radiation on mortality rate (\%) in fish fingerlings of $T$. tor and S. richardsonii.

\begin{tabular}{llll}
\hline Group & Experiments & T. tor & S. richardsonii \\
\hline Group I & Control & $5 \pm 0.6$ & $6 \pm 0.4$ \\
Group II & Retene & $6.8 \pm 0.5$ & $8 \pm 0.6$ \\
Group III & Solar radiation & $8.0 \pm 0.4$ & $10 \pm 0.7$ \\
Group IV & Artificial UV-B & $12.0 \pm 0.6$ & $16 \pm 0.6$ \\
Group V & Solar + Retene & $18 \pm 0.8$ & $23 \pm 0.5$ \\
Group VI & Artificial UV-B + Retene & $24 \pm 0.2$ & $30 \pm 0.6$ \\
\hline
\end{tabular}

Table 4. Effect of solar and artificial UV radiation on Lipid peroxidation (Malondialdehyde Nano Mole/Mg Protein) in fish fingerlings of $T$. tor and $S$. richardsonii.

\begin{tabular}{llll}
\hline Group & Experiments & T. tor & S. richardsonii \\
\hline Group I & Control & $7.18 \pm 0.18$ & $7.56 \pm 0.28$ \\
Group II & Retene & $8.35 \pm 0.50^{\mathrm{NS}}$ & $7.98 \pm 0.42^{\mathrm{NS}}$ \\
Group III & Solar radiation & $8.47 \pm 0.30$ & $8.15 \pm 0.55^{\mathrm{NS}}$ \\
Group IV & Artificial UV-B & $8.60 \pm 0.58$ & $8.22 \pm 0.40$ \\
Group V & Solar + Retene & $9.10 \pm 0.65$ & $8.50 \pm 0.62$ \\
Group VI & Artificial UV-B + Retene & $9.37 \pm 0.82$ & $8.90 \pm 0.40$ \\
\hline
\end{tabular}

Table 5. Effect of solar and artificial UV radiation on Superoxide dismutase (SOD) (unit/mg Protein) in fish fingerlings of $T$. tor and S. richardsonii.

\begin{tabular}{llll}
\hline Group & Experiments & T. tor & S. richardsonii \\
\hline Group I & Control & $0.65 \pm 0.05$ & $0.58 \pm 0.04$ \\
Group II & Retene & $0.60 \pm 0.04$ & $0.55 \pm 0.02$ \\
Group III & Solar radiation & $0.52 \pm 0.08$ & $0.48 \pm 0.06$ \\
Group IV & Artificial UV-B & $0.48 \pm 0.05$ & $0.43 \pm 0.04$ \\
Group V & Solar + Retene & $0.44 \pm 0.06$ & $0.40 \pm 0.05$ \\
Group VI & Artificial UV-B + Retene & $0.45 \pm 0.05$ & $0.42 \pm 0.07$ \\
\hline
\end{tabular}

Table 6. Effect of solar and artificial UV radiation on Catalase in fish fingerlings of $T$ tor and $S$. richardsonii with Retene.

\begin{tabular}{llll}
\hline Group & Experiments & T. tor & S. richardsonii \\
\hline Group I & Control & $82.6 \pm 1.52$ & $78.5 \pm 1.64$ \\
Group II & Retene & $74.5 \pm 1.80$ & $74.3 \pm 1.76$ \\
Group III & Solar radiation & $72.8 \pm 1.25$ & $71.8 \pm 1.38$ \\
Group IV & Artificial UV-B & $70.1 \pm 1.30$ & $68.2 \pm 1.50$ \\
Group V & Solar + Retene & $67.7 \pm 1.75$ & $65.5 \pm 1.25$ \\
Group VI & Artificial UV-B + Retene & $62.9 \pm 1.85$ & $60.1 \pm 1.70$ \\
\hline
\end{tabular}

vitamin mineral respectively were used as feeding requirement during experiments (Table 2 ).

Result on mortality rate on fish within 30 days with 3 hour of exposure to solar $\left(0.428 \mathrm{mw} / \mathrm{cm}^{2}\right)$, artificial $\left(750 \mathrm{mw} / \mathrm{cm}^{2}\right)$, UV-B and retene $(50 \mu \mathrm{g} / \mathrm{l})$ indicated highest mortality in S. richardsonii $(30 \%)$ as compared to T. tor (24\%) with UV-B + retene (Table 3). This may be due to the fact that Tor tor being a bottom feeder species generally prefers to live in bottom which may avoid the direct exposure of harmful artificial UV radiation due to photoprotection changes in skin. While, S. richardsonii prefers to live in open water thus there are more chances to get UV exposure. Artificial UV-B + retene was found more toxic than natural solar + retene. Gills malondialdehyde level, a product of lipidperoxidation and cell injury indicated an increase in lipid peroxidation level in comparison to control. Non significant change was observed after exposure of individual retene and natural solar UV. An increase was observed after exposure to solar UV and artificial UV-B radiation in the pres- ence of retene (Table 4). Antioxidative enzyme catalase indicated decrease in antioxidant potential, which decreased in all the groups in comparison to control. In the laboratory experiment UV-B induced reactive oxygen species, indicating as higher superoxide dismutase (SOD) activities in control as while UV - B and solar radiation contributed significantly to decrease the SOD units in fish larvae and acted as sole biomarker for reactive oxygen species that damaged to lipids, protein and DNA (Table 5). Significant decrease in catalase level (0.05) was found after artificial UV$B$ and retene. Glucose-6-Phosphatase activity decreased in all groups in comparison to control. Maximum reduction was observed after treatments with retene and artificial UV-B (Table 6). The larvae of $S$. richardsonii were found more sensitive than $T$. tor as indicated by high mortality rate and other pigmented characteristics observed on dorsal side. Hakkinen et al. (2002) and Bhandari and Sharma (2010) observed that due to less protection mechanism at early larval stage, 
sensitivity of Coregonid fish and Phormidium corium larvae to UV radiation was higher than other growing stages.

The studies on the effect of UV radiation have indicated that UVR may influence the respiratory systems in fishes mentioned by (Freitag et al., 1998). It was also reported to induce pigmentation in white fish, Coregonus albula, larvae (Hakkinen et al.,2004). Alemanni et al., (2003) also demonstrated an increase in oxygen consumption rate and restless behavior of juvenile rainbow trout (Oncorhynchus mykiss) due to the effect of UV radiations. Sharma et al., (2008) showed that fish survivorship model based on the exposure of UV$B$ radiation affects the survival rate of surface feeder fish, Catla catla larvae. UV radiations along with other ecological stressors are also harmful for fish species in aquatic ecosystem. Kumar et al., (2011) observed that photo toxicity of naturally occurring retene affected the growth, swimming and behavioral pattern in hill stream fish species, Barilius and Nemacheilus.

The ultraviolet light had a positive effect on pigmentation, which also affects the coloration of arthropods and fish species (Kumar et al., 2015). The UV light stimulates the chromate phores to produce more pigment on dorsal side of fish species in comparison of sun light. (Fukunish et al., 2011) and (Laura, 2011) found significant reduction in growth, mortality, damages of corneal epithelium, skin lesion and other physiological functions in larval stages of sparid fishes and whale due to direct exposures of UV radiation. The present study also observed that solar and UV -B radiation on fish larvae of $T$. tor and $S$. richardsonii caused several detrimental effects as fin blistering, eyes bulging, body curving, loss of buoyancy and dark patches (pigmentation on dorsal side).

\section{Conclusion}

The present study on monitoring of solar UV radiation showed seasonal and altitudinal variations in Himalayan region of Uttarakhand. Solar ultraviolet radiation was found maximum in summer months of July and August $\left(1.192 \mathrm{mw} / \mathrm{cm}^{2}\right)$ at higher altitude during the year 2017-18. Artificial UV-B had a stronger damaging effect than solar radiation and became highly toxic in a presence retene to fingerlings of $T$. tor and $S$. richardsonii fish species. Natural solar radiation contained combination of wavelength thus may have protective interaction than pure artificial UV radiation. The fingerlings of fish, S. richardsonii were found more sensitive than $T$. tor may be due to food habits, habitats and genetic variations. Hill stream fish fingerlings may be used as a model for aquatic phototoxicological studies as predicted ecosystem productivity modelling of aquatic ecosystem.

\section{ACKNOWLEDGEMENTS}

The author (Dr. Sunil Kumar) is highly thankful to UGC New Delhi for providing instrumental support.

\section{REFERENCES}

1. Alemanni, M. E., Lozada, M. and Zagarese, H.E. (2003). Assessing sublethal effects of ultraviolet radiation in juvenile rainbow trout (Oncorhynchus mykiss). Photochemical and photobiological Sciences, 2(8): 867-870. (DOI: 10.1039/B301564E)

2. Arts, M. T., Browman H. I., Jakinen E. I., Kuhn P. S. and Skiftesvik A. B. (2010). Effects of UV radiation and diet on polyunsaturated fatty acid in the skin, ocular tissue and dorsal muscle of Atlantic salmon (Salmo salar) held in outdoor reading tanks. Photochem. Photobiol, 86: 909.

3. Bhandari, R.R. and Sharma, P.K. (2010). UV- B radiation and high light induced oxidative damage in Phormidium corium may cause bleaching to associated coral reefs. Indian Journal of Geo-Marine Science, 39: 423- 429.

4. Blautein, A.R., Belden, L.K., Hatch, A.C., Kats, L.K., Hoffman, P.D., Hays, J.B., Marco, A., Chivers, D.P and Kiesecker, J.M. (2002). In ecosystem, evolution and ultraviolet radiation. Springer-Verlag, Newyork.63.

5. Buzzi, F. (2002). Phytoplankton assemblages in two sub-basins of lake. Como. J. Limnol., 61(1): 117128.(DOI:10.4081/jlimnol.2002.117)

6. Dargaei, Z., Sharifpour, I. and Zorriehzahra, J. (2014). UV-B impacts on morphology of retina of Oncorhynchus mykiss larvae. Iranian Journal of Fisheries Sciences, 13(2): 289-302.

7. David, I.P. and Davies, M. (2006). Actions of Ultraviolet light on cellular structures. Carcinogens and Genomic Intability. 96, 131.

8. De Mora, S.J., Demers, S., Vernet M. (2000). The effects of UV radiation on marine ecosystems.Cambridge University Press, Cambridge, 324 pgs.

9. Figueroa, F.L., Jiménez, J., Pérez-Lloréns, J.L., Niell, F.X. (1996). Underwater light and algal photobiology. Sci Mar 60 (Supl. 1), Instituto de Ciencias del Mar, C.S.I.C. Barcelona, Spain.

10.Frederick, J.E., Díaz, S.B., Smolskaia, I., Espósito, W., Lucas, T., Booth, C.R. (1994). Ultraviolet solar radiationin the high latitudes of South America. Photochem Photobiol, 60: 356-362. (https:// doi.org/10.1111/j.1751-1097.1994.tb05115.x)

11.Freitag, J.F., Steeger, H.U., Storz, U.C., and Paul, R.J. (1998). Sublethal impairment of respiratory control in plaice (Plueronectes platessa) larvae induced by $W-B$ radiation, determined using a novel biocybemetical approach. Marine Biology, 132: 1-8. (DOI: 10.1007/s002270050366).

12.Fukunishi, Y., Masuda, R. and Yamashita,Y. (2011). Exposure of eggs to solar UV-B leads to reduced hatching rates in two sparid fishes, red sea bream Pagrus major and Black sea bream Acanthopagrus schlegeli. J. Fish Biol, 76. 734.

13. Hakkinen, J., Vehniainen E, Oikari, A. (2004). High sensitivity of northern pike larvae to UV-B but no UVphotoinduced toxicity of retene. Aquat Toxicol, 66: 393-404. (DOI:10.1016/j.aquatox.2003.11.001).

14. Hakkinen, J., Vehniainen, E. and Oikari, A. (2004). 
High sensitivity of northern pike larvae to UV-B but no UV-photoinduced toxicity of retene. Aquat Toxicol,66: 393-404.DOI: 10.1016/j.watres.2004.04.004

15. Hakkinen, M.J., Vehniainen, E., Ylonen, O., Heikkilla, J., Soimasuo, M., Kaurola, J., Oikari, A. and Karjalainen, J.S. (2002). The effects of increasing UV-B radiation on pigmentation, growth and survival of coregonid embroys and larvae. Environmental Biology of Fish, 64: 151-159.

16.Kumar, S., Kumari, P. and Mishra, P. (2011). Lipidperoxidation and mortality in fish larvae after solar ultraviolet radiation. Journal of Environmental Research and development, 5(4): 898-904.

17.Kumar, S., Kumari, P. and Mishra, P. (2011). Lipidperoxidation and mortality in fish larvae after solar ultraviolet radiation. Journal of Environmental Research and development, 5(4): 898-904.

18.Kumar, S., Nagar, S. and Choudhary, N. (2015). Effect of ultraviolet radiation and temperature change on zooplankton- Cladocera and Copepoda. Int. J. Pharmacol. Bio. Sci, 9(3): 1-7.

19.Laura S., Isola D., Zucconi L. and Onofri S. (2011). Resistance to UV-B induced DNA damagein extreme - tolerant cryptoendolithic Antarctic fungi detection by PCR assays. Fungal Biology. 115(10): 937- 944.

20.Lin J.Y. and Fisher D.E.(2007).Melanocyte biology and skin pigmentation. Nature, 445:843.

21.Madronich, S. (1993). The atmosphere and UV-B radiation at ground level. In: Young AR, Björn LO, Moan J, Nultsch W (eds) Environmental UV photobiology. Plenum Press, New York, pp 1-39.

22.Markkula, E.,Salo, H.M., Rikalainen, K.and Jokinen, I.E. (2009). Long- term UVB Irradiation affects the Immune function of Carp (Cyprinus carpio) and rainbow trout (Oncorhynchus mykiss). Photochem. Photobiol. 85. 347.

23.McKenzie, R.L., Björn, L.O., Bais, A., and llyasd, M. (2007). Changes in biologically active ultraviolet radiation reaching the Earth's surface. Photochemical and Photobiological Sciences, 2: 5-15
24.Scott, R.C., Schuldiner, O., Neufeld, T.P. (2004). Role and regulation of starvation-induced autophagy in the Drosophila fat body. Dev. Cell 7(2): 167-178.

25.Sharma, J., Mittal, P. and Chakrabarti, R. (2008). Development of survivorship model for UV-B irradiated Catla catla larvae. Aquatic Ecology. 42(1): 17 23.(DOI: 10.1007/s10452-006-9069-8)

26.Singh, V.P., Srivastava P.K., and Prasad, S.M. (2012). Differential effects of UV-B radiation fluence rates on growth, photosynthesis, and phosphate metabolism in two cyanobacteria under copper toxicity. Toxicological and Environmental Chemistry, 94(8): 1511-1535.

27.Smith, C.V. and Anderson, R.E. (1987). Methods for determination of lipid peroxidation in biological samples.Free Radic Biol Med, 3(5): 341-344.

28.Sommaruga, R. Oberleiter, A. Psenner, R. (1996). Effect of UV radiation on the bacterivory of aheterotrophic nanoflagellate. Appl Environ Microbiol, 62: 4395-4400.

29.Speekmann, C.L., Bollens, M.S. and Avent, S.R. (2000). The effects of ultraviolet radiation on the vertical distribution and mortality of estuarine. $J$. Plankton. Res, 22: 2325-2350.

30.Takahara. S., Hamilton, J.V., Neat and Kabara, T.V. (1960). Hypocatalaasemic. A new genetic carrier state. J. Clin. Invest 39:610.

31.Ukeda, H. Sarker, A.K. Kawana D., Sawamura, M. (1999). Flow injection assay of superoxide dismutase based on the reduction of highly water- soluble tetrazolium. Anal Sci, 15:353-357.

32.Uraiwan, P., Sittithumcharee, G., Rathviboon, N. and Siwanon, J. (2016). Ultraviolet RadiationInduced Skin Aging:The Role of DNA Damage and Oxidative Stress in Epidermal Stem Cell Damage Mediated Skin Aging. Stem Cells International ,1: 116 DOI: (10.1155/2016/7370642)

33.Zarrati, F., Forno, R., Fuentas, J., and Andrade, M. (2003). Erythemally weighted UV variations at two high altitude locations. J. Geophys. Res., 108:1-6 